\title{
Peri-Urban Transformations in Agricultural Landscapes of Perugia, Italy
}

\author{
Marco Vizzari \\ Department of Man and Territory, University of Perugia, Perugia, Italy \\ E-mail: marco.vizzari@unipg.it \\ Received January 18, 2011; revised February 11, 2011; accepted February 15, 2011
}

\begin{abstract}
Urban fringes represent very complex landscapes because of their proximity and mutual dependency with cities and rural areas. These landscapes may be considered as transition entities characterized by fuzzy boundaries. An uncontrolled development of urban sprawl and land use changes in these areas may determine negative impacts on all natural, economic and social components. Thus, urban fringes assume a key-role in modern landscape analysis, planning and management. Landscape analysis of these interfaces, as this study shows, can be effectively supported by GIS spatial modelling. The Settlement Density Index (SDI), developed through GIS spatial analysis techniques, expresses punctually the territorial gradients generated by the presence of settlements and allows the identification of the urban fringes in the two periods under investigation. These areas are then characterized and analyzed quantitatively using detailed land use data. The comparison of the diachronic information highlights the transformations of peri-urban landscapes that appear mainly related to the modifications of spatial configuration of urban areas and to the changes of agricultural systems.
\end{abstract}

Keywords: Landscape Analysis, Density Analysis, Urban Fringes, GIS, Land Use Transformations, Morphological Spatial Pattern Analysis

\section{Introduction}

Peri-urban areas represent very complex territorial spaces from the economic, environmental and social viewpoints, particularly in relation to their proximity and mutual dependence with cities and rural areas [1]. Agriculture has a strategic value for the balance and quality of the urban environment within these tracts of land [2,3].

The concept of "peri-urban" is subject to numerous interpretations by planners who are unable to offer unambiguous criteria for the identification and territorial delimitation of these spaces [4]. In reality, they represent spaces with undefined boundaries [5] along the urbanrural gradient, inside of which transitions and changes in equilibrium and relationships can be observed [6,7].

The view of landscapes as continua and spatial gradients represents a challenge to the conventional view of how the natural (and human) environment is organised [8]. Urbanization can also be considered as a complex environmental gradient that produces modifications on the structures and functions of ecological systems with a magnitude dependent on the steepness of the same gra- dient $[9,10]$.

The uncontrolled urban sprawl and transformations of land use in peri-urban areas have strong negative impacts on all the natural, economic and social components [11]. Thus, landscape analysis planning of these interfaces has a significant role, not only for the quality of life of those living in such areas, but also for the entire sustainability of the urban and rural development [12].

Analysis of the dynamics of complex territorial systems such as peri-urban areas, an essential prerequisite for planning, requires robust methods and advanced technologies [13]. Geographical information systems, through the integration of several different analytical functions, offer an effective platform for the spatial analysis and modelling of geographical data, thanks to which it is possible to improve our understanding of real world dynamics [14]. GIS spatial modelling can support the definition and calculation of continuous indicators allowing better assessment and interpretation of the gradients characterising landscape [15]. GIS techniques allow improved understanding of the specific characteristics of sites and the nature of the interactions between 
human and natural actions in landscape configuration [16].

In this study landscape gradients produced by settlements are modelled implementing a density spatial index. Through the analysis of the settlement indices for the two years under investigation are detected the spatial modifycations of urban gradient. Moreover, specific transformations of peri-urban landscape are explored through diachronic land use analysis.

\section{Methods}

The study area is represented by the Umbrian municipalities of Perugia and Corciano which encompass an urban and productive tissue of high territorial continuity [17] (Figure 1). The land use data used for the analysis was extracted from the Regional Land Information System while the orthophoto was retrieved, via WMS, from the National Cartographic Portal. Land use data, available for the years 1977 and 2000, currently are the only detailed scale resources available for the land use of the area in question (Table $\mathbf{1}$ ).

Prior to proceed to subsequent data processing, land use polygons were converted in raster format at a resolution of $10 \mathrm{~m}$, maintaining adequate polygonal shape detail in accordance with the scale of the analysis [18]. The built-up class has been subjected to extensive processing based on morphological analysis methods aimed at segmenting binary patterns of settlements into mutually ex-

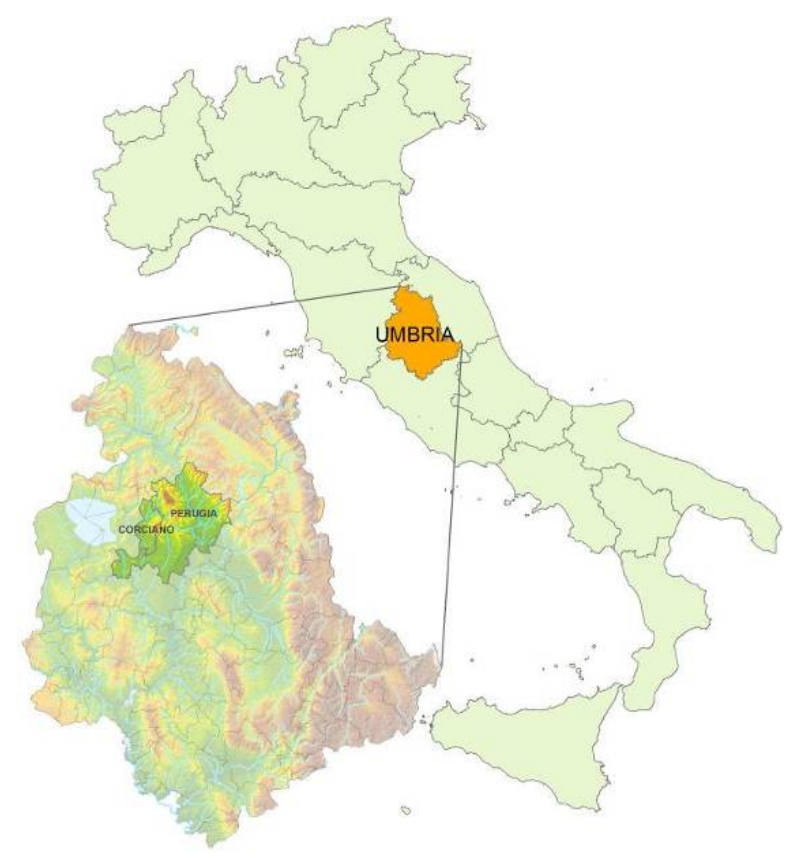

Figure 1. Location of the area of interest (Municipalities of Perugia and Corciano, Umbria, Italy). clusive categories: core, islet, loop, bridge, perforation, edge, and branch [19] (Figure 2).

The pixels classified as bridge, edge and loop categories were eliminated because of their coincidence with road infrastructures. In the other categories, using the orthophoto as background, a subsequent visual selection of settlements was conducted (urban centres, commercial and production areas, inhabited nuclei and dispersed settlements) within other areas, classified as "built-up" in the 1977 and 2000 land use data.

Using GIS density analysis techniques, a density index was calculated measuring the spatial incidence of settlements (SDI - Settlement Density Index). GIS density analysis takes known quantities of certain phenomena and spreads them across the landscape based on the quantity measured at each location and the spatial relationship of the locations of the quantities measured [20].

Unlike simple density, kernel density estimation (KDE) produces smoother surfaces, better representing land-

Table 1. Essential metadata of the land use datasets.

\begin{tabular}{|c|c|c|}
\hline Dataset & Land use 1977 & Land use 2000 \\
\hline Data source & $\begin{array}{l}\text { Visual interpretation of } \\
\text { orthophoto and } \\
\text { subsequent manual } \\
\text { digitizing of polygons }\end{array}$ & $\begin{array}{c}\text { Update of } 1977 \\
\text { dataset using visual } \\
\text { interpretation and } \\
\text { heads-up digitizing on } \\
\text { digital orthophoto }\end{array}$ \\
\hline Format & Vector - ESRI shapefile & Vector - ESRI shapefile \\
\hline Map units & Meters & Meters \\
\hline $\begin{array}{l}\text { Reference } \\
\text { scale }\end{array}$ & $1: 10.000$ & $1: 10.000$ \\
\hline $\begin{array}{l}\text { Time period } \\
\text { content }\end{array}$ & Spring 1977 & Spring 2000 \\
\hline $\begin{array}{l}\text { Coordinate } \\
\text { system }\end{array}$ & $\begin{array}{c}\text { Rome } 1940 \text { - Gauss } \\
\text { Boaga Est }\end{array}$ & $\begin{array}{c}\text { Rome } 1940 \text { - Gauss } \\
\text { Boaga Est }\end{array}$ \\
\hline
\end{tabular}

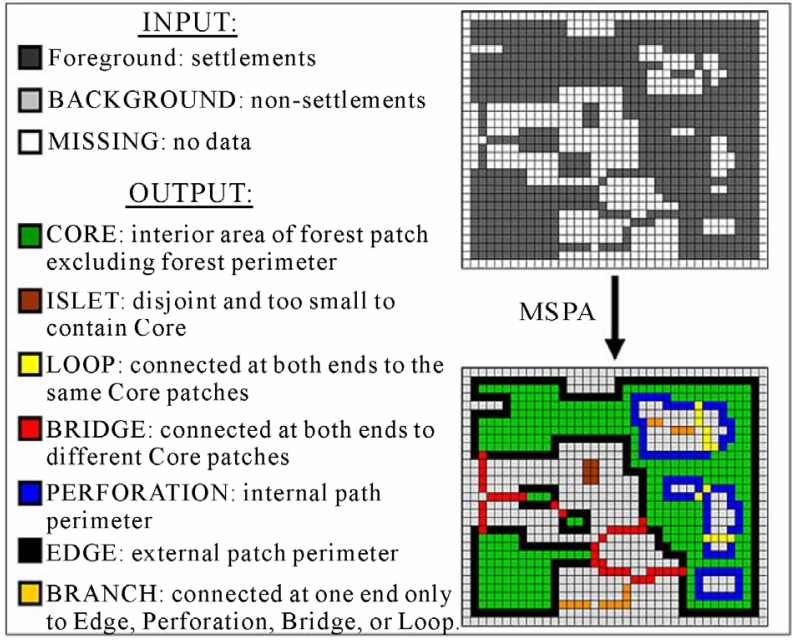

Figure 2. Output of MSPA procedures (adopted from Soille \& Vogt, 2009). 
scape gradients [15], since the resulting surfaces surrounding each point are based on a quadratic formula with the highest value at the centre of the surface (the point location) tapering towards zero at the search radius distance. In GIS-based KDE functions, varying output raster resolutions and search radii can be defined [21]. Cell resolution, in this case also set at $10 \mathrm{~m}$, was defined according to the analysis scale [18]. Different search radii allow analysis of the phenomena at different scales, since a wider radius shows a more general trend over the study area, smoothing the spatial variation of the phenomenon, while a narrower radius highlights more localised effects such as 'peaks and troughs' in the distribution [22]. A good rule is to test different search radius values in order to examine variation in the function at different scales [23]. In this particular application, as suggested by Murgante et al. [4], a radius of $400 \mathrm{~m}$ was adopted in the analysis of settlement density at the working scale. Prior to calculating density, polygonal landscape elements were converted to a mesh of points spaced at intervals equal to the size of the cells used for density analysis. This allowed a proper resolution to be set, maintaining adequate polygonal shape detail in accordance with the scale of the analysis. Through this index the territorial gradients generated by the presence of settlements were represented as a continuous surface in raster format (Figures $\mathbf{3}$ and $\mathbf{4}$ ).

The SDI, expressed as the $\mathrm{km}^{2}$ of surface occupied by settlements over the $\mathrm{km}^{2}$ of the territorial surface, as- sumes maximum values in the central portions of more extensive urban areas, decreasing progressively as we move towards rural areas. The local variations of the SDI were studied in GIS environment through map algebra and slope analysis. In the SDI surface a particular transition zone has been observed (with values of between 0.1 and 0.5 ) on which has been identified spatially the peri-urban areas analyzed in this study. With the aim of quantitatively analysing the land use forms and the relevant transformations occurring over the period of time under consideration, these areas have been characterised by GIS overlay mapping with the corresponding land use data.

\section{Results and Discussion}

During the period under investigation has occurred a consistent increase in urbanised areas, which, in total, equal approx. 30\% with 1190 ha. This increase has produced a territorial expansion of the peri-urban area which equal to an area of approx. 1934 ha. It is interesting to note how the increase in peri-urban areas is significantly greater than that recorded for the urbanized occupied areas. This confirms how, for obvious reasons, the territorial impact of the peri-urban fringes is destined to grow much more rapidly than the areas with settlements.

Spatial analysis of variations in SDI, obtained, using GIS map algebra, by comparing the data pertaining to 1977 and 2000, shows precisely the changes of the
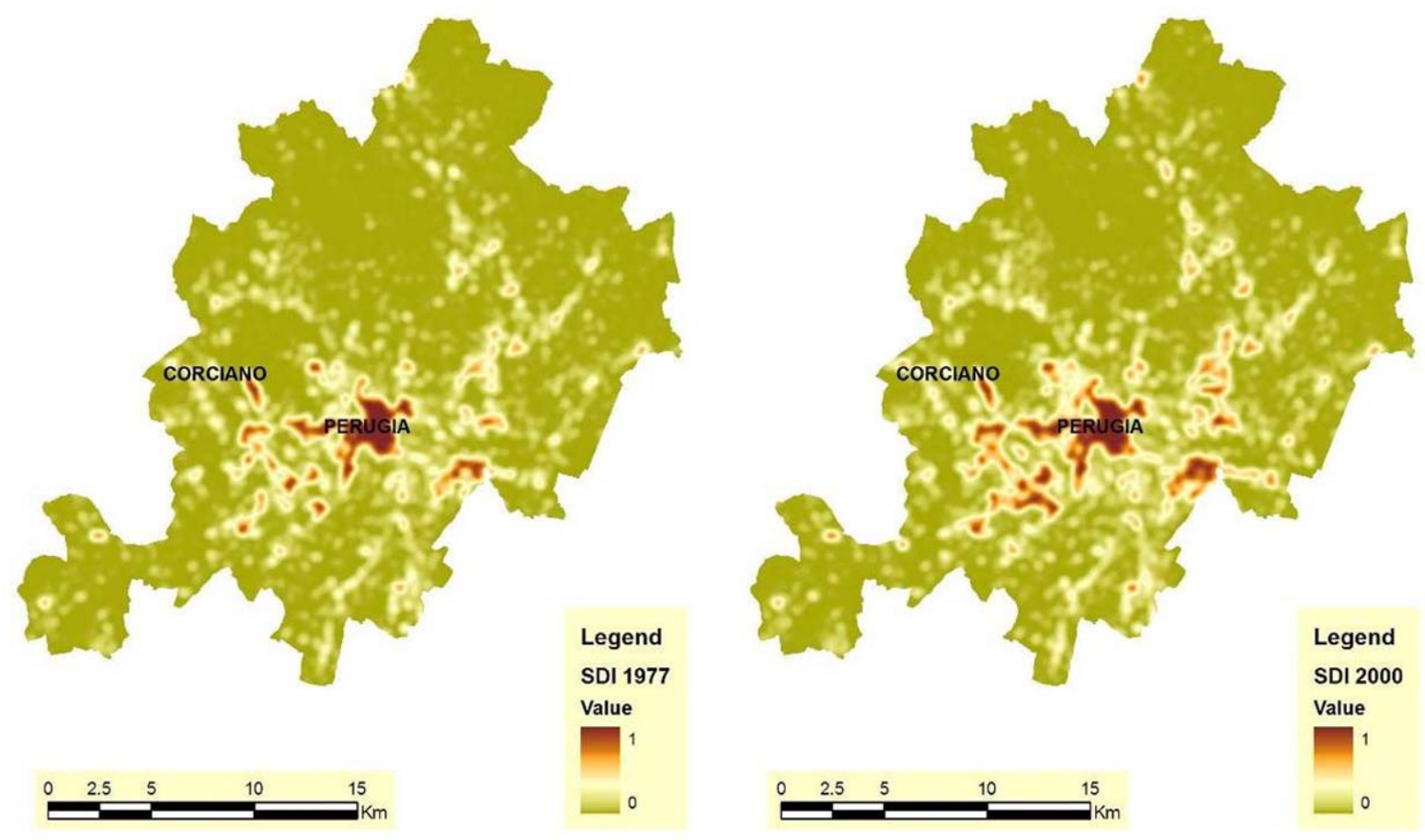

Figure 3. SDI of the years 1977 and 2000. 


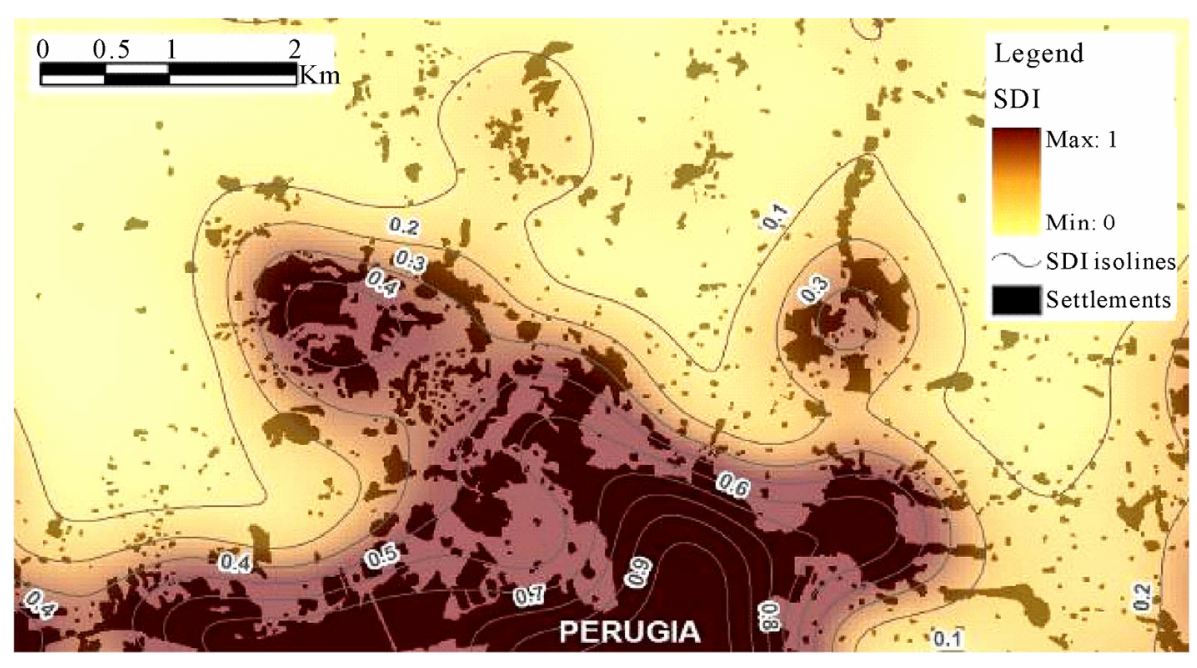

Figure 4. SDI of year 2000 and relative isolines. Detail in the area to the north of Perugia.

territorial gradients generated by urban sprawl occurred in this period (Figure 5). The greatest changes in SDI are observed in the broad recently urbanised areas, shown by darker colouration, with variations in SDI $>0.2$. Around these areas are observed modifications, varying in extent, resulting from the growing of settlement gradients (represented by the progressively lighter colours).

The modifications of urban gradient, generated by urban growth within study area, are also measured through the spatial analysis of the steepness of SDI variation (Figure 6). The greater increments, highlighted by darker colouration, can be detected in the area of plain around Perugia where new commercial buildings were constructed within agricultural areas. Other relevant increases of SDI slope, represented by the lighter colours, can be observed in new residential areas located in the western and in southern parts of the city. In these two contexts, with reference to settlement density, the transitions between urban and rural areas have become tendentially sharper compared to the late 1970s. Particularly on the plains, around the most recently urbanized areas, increasingly sharper transitions are observed due to the greater density of settlements and, as will be observed later, due to the progressive loss of the traditional agricultural uses. Generally, in the last decades, no attention has been paid to the planning of new peri-urban spaces, and residential or commercial complexes of high territorial density become included within traditionally agricultural areas, resulting in a high level of variation in settlement gradients.

The significant polycentric development described above produced an evident corresponding change in the spatial configuration of the peri-urban areas (Figure 7). Diachronic analysis of land use highlights clear modifycations in these areas within the period under considera- tion (Table 2). Along with the cultivated areas, the urban portions maintain a constant proportion (approx. 26\% and $64 \%$ respectively) and continue to play an essential role in characterising the contexts under investigation.

Specifically, in relation to agricultural land use, olive groves occupy an almost unchanged surface area (approx. $8.5 \%$ ), while sowable lands are increased by around $10 \%$ (reaching approx. 46\%) at the expense of the other agricultural crops such as sowable lands with trees and specialised vineyards in particular. On the one hand, this phenomenon is linked to the progressive simplification of agricultural systems taking place in Umbria since the late 1950s [24], and on the other hand, to the altered spatial configuration of the peri-urban areas in the two time periods under consideration.

Indeed, as may be observed, the progressive expansion

Table 2. Main land uses in peri-urban areas and relative variations, years 1977 and 2000.

\begin{tabular}{|c|c|c|c|c|c|c|}
\hline \multirow{2}{*}{ Land use } & \multicolumn{2}{|c|}{ Sup. 1977} & \multicolumn{2}{|c|}{ Sup. 2000} & \multicolumn{2}{|c|}{ Variation } \\
\hline & ha & $\%$ & ha & $\%$ & ha & $\%$ \\
\hline $\begin{array}{l}\text { Sowable } \\
\text { lands with } \\
\text { trees }\end{array}$ & 1248 & 14.2 & 615 & 5.8 & -633 & -50.7 \\
\hline Vinegards & 580 & 6.6 & 331 & 3.1 & -250 & -43.0 \\
\hline $\begin{array}{c}\text { Other arboral } \\
\text { uses }\end{array}$ & 17 & 0.2 & 7 & 0.1 & -10 & -60.1 \\
\hline Olive groves & 761 & 8.7 & 905 & 8.5 & 143 & 18.8 \\
\hline Woodlands & 660 & 7.5 & 949 & 8.9 & 289 & 43.7 \\
\hline Built-up & 2315 & 26.4 & 2821 & 26.4 & 506 & 21.8 \\
\hline $\begin{array}{c}\text { Sowable } \\
\text { lands }\end{array}$ & 3101 & 35.4 & 4963 & 46.4 & 1862 & 60.0 \\
\hline TOTAL & 8757 & 100 & 10691 & 100 & 1934 & 22.1 \\
\hline
\end{tabular}




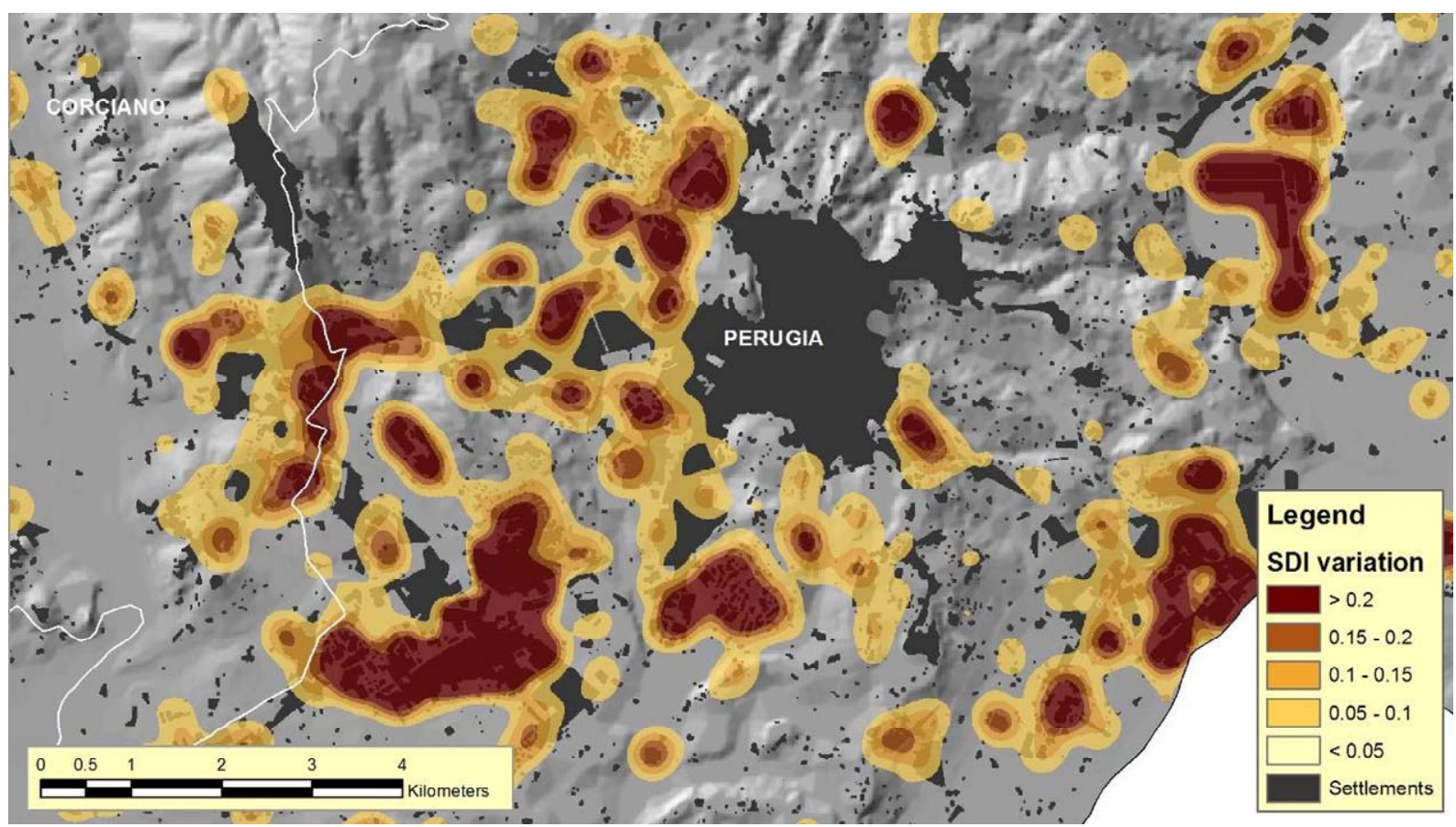

Figure 5. Variations in settlement density within the Perugia area.

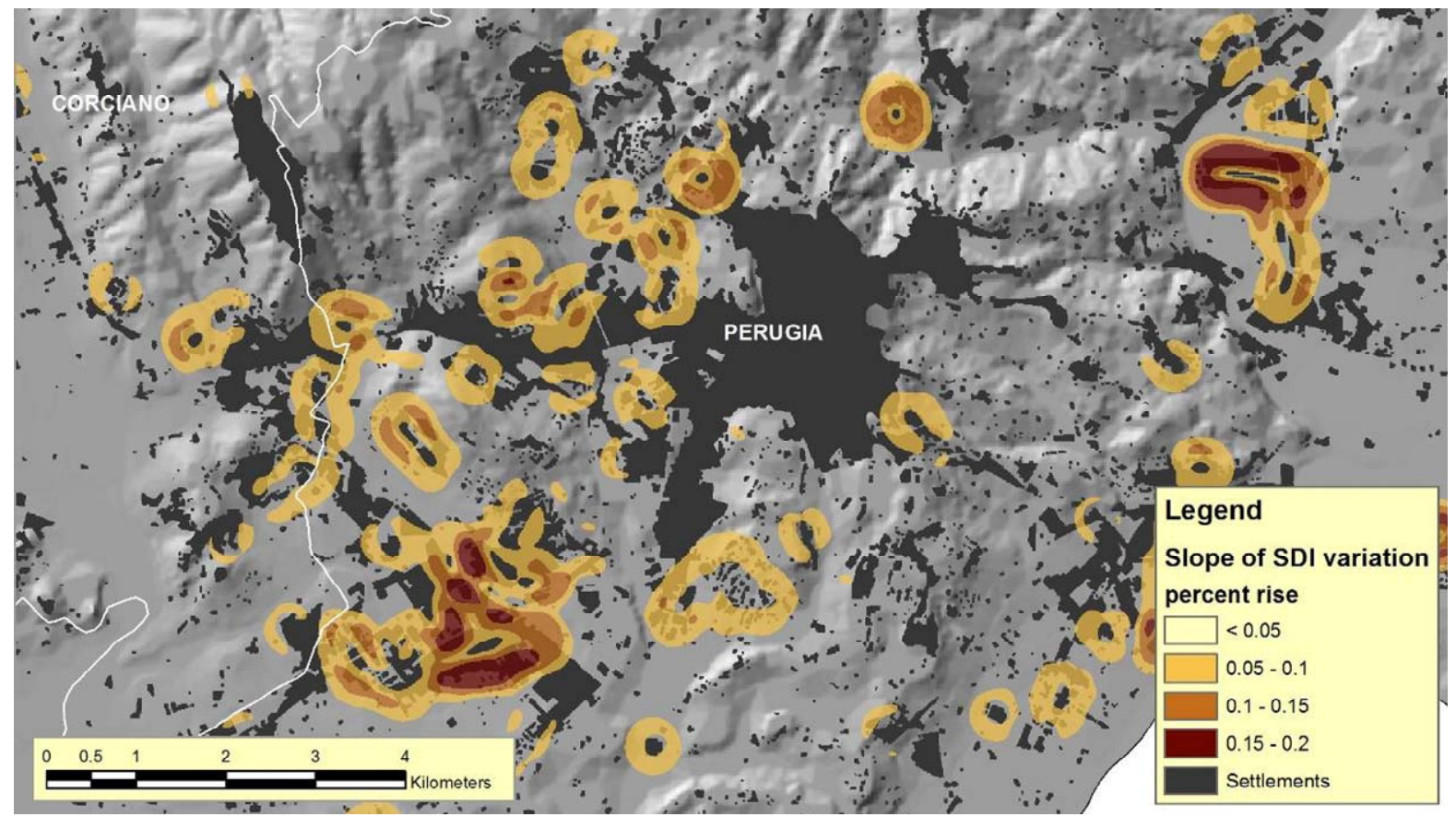

Figure 6. Slope of SDI variation in percent rise.

of settlements has resulted in the spreading of certain peri-urban areas into more intensive agricultural areas, traditionally occupied by simple crops (Figure 8).

\section{Conclusions}

As the study has shown, the use of GIS-based density indices allows modelling of settlements gradients and quantify their transformations during time. In some areas of the territory under investigation, a generalized increase in settlement density and the expansion of the same has altered the typical Umbrian peri-urban gradients characterised by a more gradual transition between rural and urban environments. 


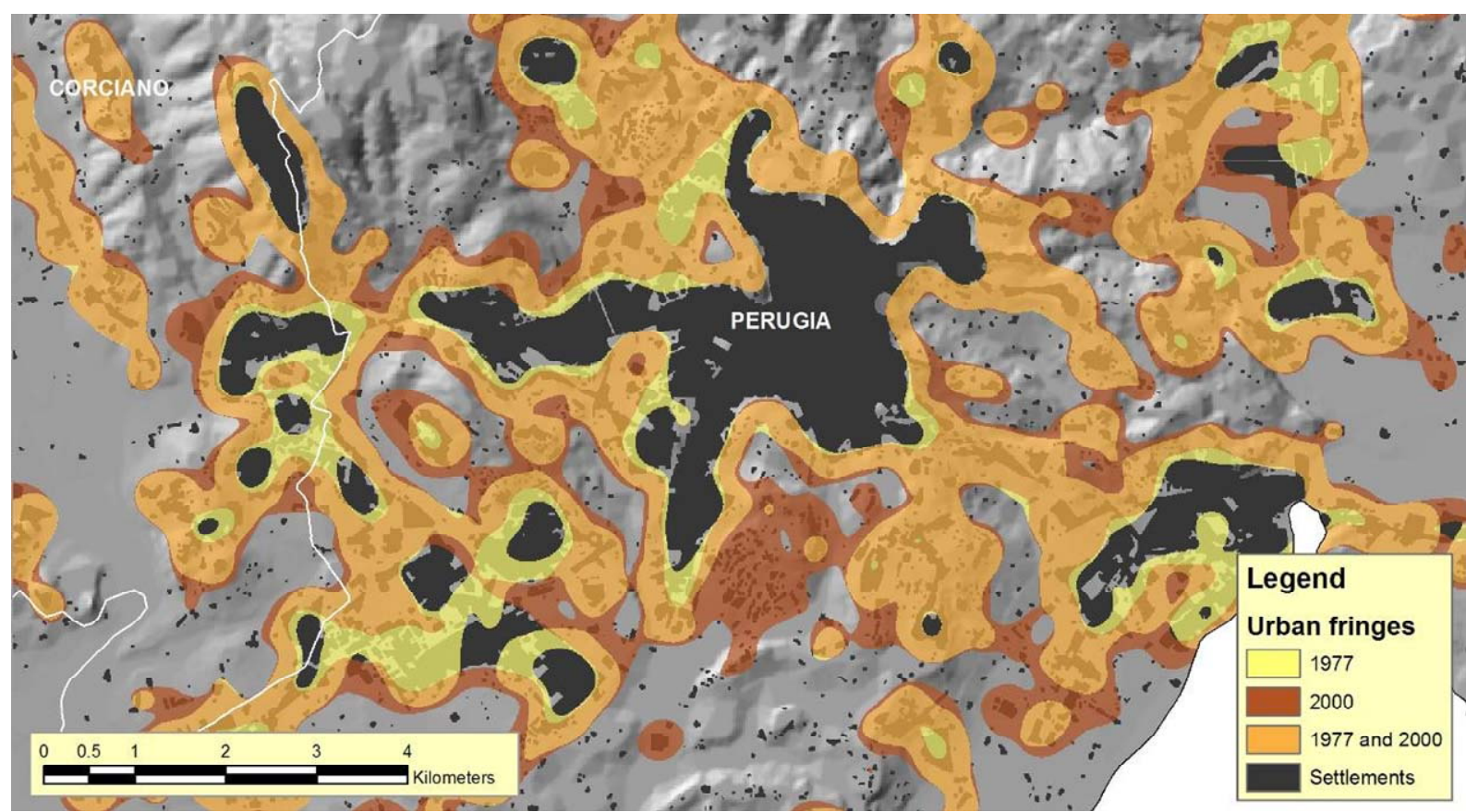

Figure 7. Development of peri-urban areas in the Perugia area between 1977 and 2000.
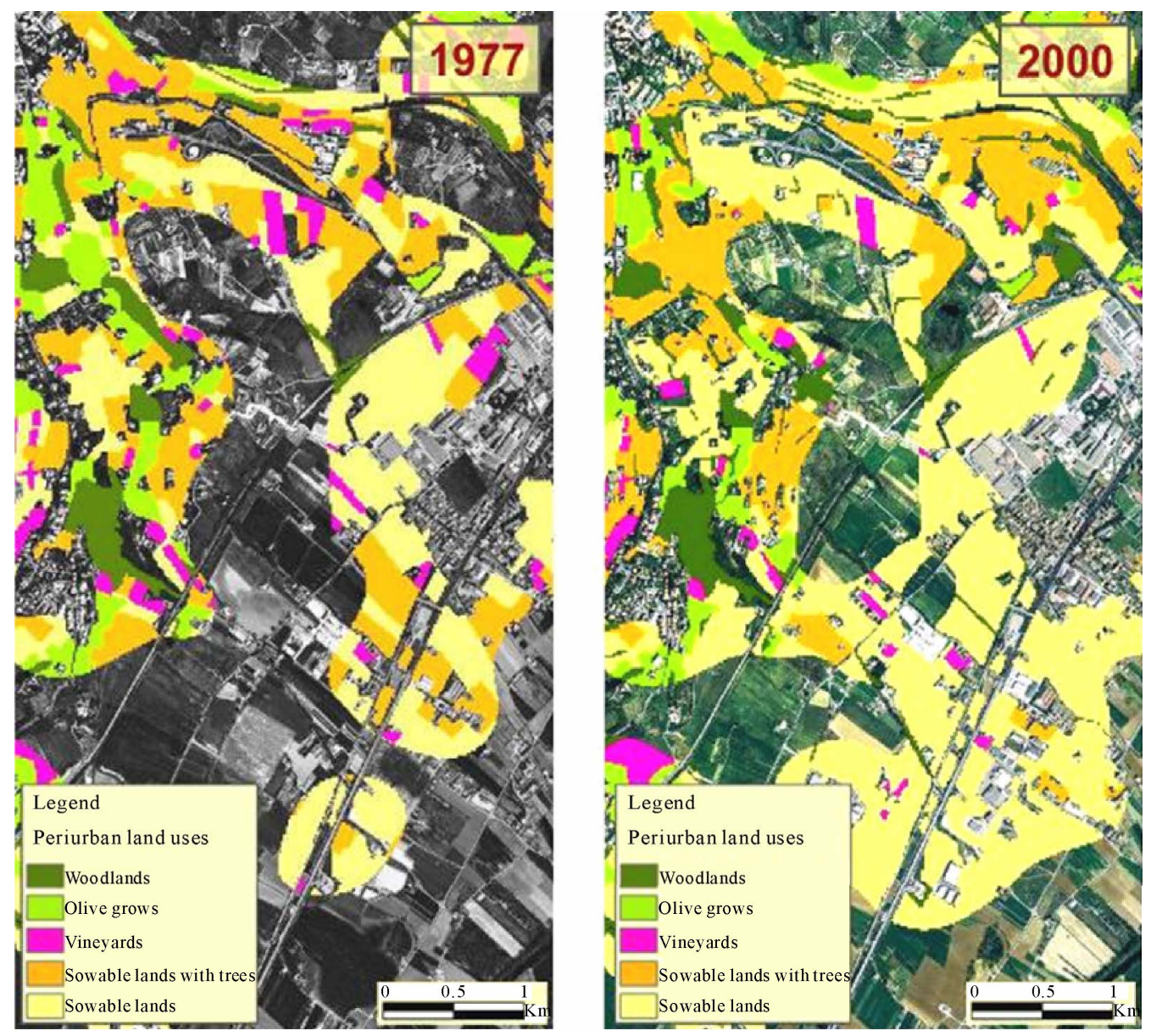

Figure 8. Expansion of urban fringes into agricultural areas south-east of Perugia. 
Diachronic analysis has effectively showed up the spatial configuration changes for the peri-urban areas and the transformations in land use occurring there between 1977 and 2000. Additional thematic information relating to historic and current land use will allow expansion of the time range and will provide further very useful information for the planning and management of these environments.

In order to study the structural changes in these landscapes more thoroughly, it will be possible to include more specific data (including land registry and census data) relating to the agricultural and urban systems. Moreover the use of advanced image processing methodsbased on object-oriented and graph-based algorithms [25] can allow the automatic or semi-automatic interprettation of high resolution satellite images and the extraction of elements characterising these landscapes. GIS modelling of peri-urban gradients variables and applying evaluation methods based on multicriteria techniques and Fuzzy logic $[4,26,27]$.

As pointed up in this study, peri-urban landscapes play an increasingly significant role in the planning and man agement of the Umbrian territory. This is confirmed by the progressive expansion of these contexts and the profound transformations to which they are subject. Despite all these transformations agriculture and related activities continue to have a fundamental role in peri-urban landscape. Therefore, it is hoped that more targeted requalification policies be developed, in which agricultural activities are no longer marginal, but acquire an increaseingly central function.

\section{References}

[1] C. Tacoli, "Rural-Urban Interactions: A Guide to the Literature," Environment and Urbanization, Vol. 10, No. 1, 1998, pp. 147-166. doi: $10.1177 / 095624789801000105$

[2] European Economic and Social Committee, Peri-urban agriculture, Opinion No. 1209, 2004.

[3] R. E. Romagna, "Lungo I Bordi"-Progetto Diriqualificazione del Paesaggio Agrario di Margine, Quaderno Tecnico, 2008.

[4] B. Murgante, L. Casas, G. A. Sansone, "A spatial rough set for locating the periurban fringe." In Batton-Hubert M., Joliveau T. and Lardon S. (dir.), Rencontres internationales Géomatique et territoire, SAGEO,2007.

[5] P. A. Burrough and A. U. Frank, "Geographic Objects with Indeterminate Boundaries," Taylor \& Francis, London, 1996.

[6] J. Cavailhès, D. Peeters, E. Sekeris and J. Thisse, "The Peri-Urban City: Why to Live between the Suburbs and the Countryside," Regional Science and Urban Economics, Vol. 34, No. 6, 2004.

[7] A. Valentini, "Il Senso del Confine - Colloquio con Piero
Zanini," Progettare sui limition Ri-Vista Ricerche per la progettazione del paesaggio, Università degli Studi di Firenze, anno 4, numero, 70-74, Firenze University Press, Firenze.

[8] L. M. Bridges, A. E. Crompton and J. A. Schaefer, "Landscapes as Gradients: The Spatial Structure of Terres-trial Ecosystem Components in Southern Ontario," Eco-Logical Complexity, Vol. 4, 2007, pp. 34-41. doi:10.1016/j.ecocom.2006.05.001

[9] M. J. McDonnell and S. T. A. Pickett, "Ecosystem Structure and Function along Gradients of Urbanization: An Unexploited Opportunity for Ecology," Ecology, Vol. 71, No. 4, 1990, pp. 1231-1237.

[10] M. J. McDonnell and A. K. Hahs, "The Use of Gra-Dient Analysis Studies in Advancing Our Understanding of the Ecology of Urbanising Landscapes: Current Status and Future Directions," Landscape Ecology, Vol. 23, No. 10, 2008, pp. 1143-1155. doi:10.1007/s10980-008-9253-4

[11] R. M. Brook and J. D. Davila, "The Peri-Urban Interface: A Tale of Two Cities," University of Wales and Development Planning Unit, University College London, UK, 2000.

[12] A. Allen, "Environmental Planning and Management of the Peri-Urban Interface: Perspectives on an Emerging Field," Environment and Urbanization, Vol. 15, No. 1, 2003, pp. 135-148.

[13] A. G. Wilson, "Ecological and Urban Systems Models: Some Explorations of Similarities in the Context of Complexity Theory," Environment and Planning, Vol. 38, No. 4, 2006, pp. 633- 646. doi:10.1068/a37102

[14] M. F. Goodchild, "Geographical Information Science International," Journal of Geographical Information Systems, Vol. 6, 1992, pp. 31-45. doi:10.1080/02693799208901893

[15] M. Vizzari, "Spatial Modelling of Potential Landscape Quality," Applied Geography, Vol. 31, No. 1, 2011, pp. 108-118. doi:10.1016/j.apgeog.2010.03.001

[16] T. Blaschke, "The Role of the Spatial Dimension within the Framework of Sustainable Landscapes and Natural Capital," Landscape and Urban Planning, Vol. 75, No. 3-4, 2006, pp. 198-226. doi:10.1016/j.landurbplan.2005.02.013

[17] Regione Umbria, RERU-Rete Ecologica Regionale dell'Umbria, Petruzzi Editore, Perugia, 2009.

[18] T. Hengl, "Finding the Right Pixel Size," Computers \& Geosciences, Vol. 32, No. 9, 2006, pp. 1283-1298. doi:10.1016/j.cageo.2005.11.008

[19] P. Soille and P. Vogt, "Morphological Segmentation of Binary Patterns," Pattern Recognition Letters, Vol. 30, No. 4, 2009, pp. 456-459. doi:10.1016/j.patrec.2008.10.015

[20] ESRI. ArcGIS Desktop Help, Release 9.2. Environmental Systems Research Institute, Redlands, CA, USA, 2007.

[21] M. J. Smith, M. F. Goodchild and P. A. Longley, "Geospatial Analysis: A Comprehensive Guide to Principles, Techniques and Software Tools," Troubador Publishing, 
Leicester, UK, 2007.

[22] G. Borruso, "Network Density Estimation: A GIS Approach for Analysing Point Patterns in a Network Space," Transactions in GIS, Vol. 12, No. 3, 2008, pp. 377-402. doi:10.1111/j.1467-9671.2008.01107.x

[23] T. C. Bailey and A. C. Gatrell, "Interactive Spatial Data Analysis," Harlow, Longman, 1995.

[24] H. Desplanques, "Campagne Umbre Contributo Allo Studio dei Paesaggi Rurali Dell'Italia Centrale," traduzione di A. MELELLI s.n.t., Quaderno della Regione dell'Umbria, No. 10, 1975.
[25] S. Aksoy and E. Dogrusoz, "Modelling Urbanizetion Using Spatial Building Patterns," Proceedings of 4th $I A P R$, Int. Workshop on Pattern Recognition in Remote Sensing, Hong Kong, 2006.

[26] J. R. Eastman, , (1999) "Multi-criteria evaluation and GIS." In: P. A., Goodchild, M. F., Maguire, D. J., and Rhind, D.W., Eds., Geographical Information Systems, Longley, John Wiley and Sons, New York, pp. 493-502.

[27] J. Malczewski, "GIS and Multicriteria Decision Analysis,” John Willey \& Sons Inc., New York, 1999. 